\title{
Development of New Chip Products from Brewer's Spent Grain
}

\author{
Reann Garrett, ${ }^{1}$ Danielle Bellmer $\mathbb{D}^{1,2}$ William McGlynn, ${ }^{1,3}$ and Patricia Rayas-Duarte $\mathbb{D}^{1,4}$ \\ ${ }^{1}$ Robert M Kerr Food and Agricultural Products Center, Oklahoma State University, Stillwater, OK, USA \\ ${ }^{2}$ Department of Biosystems \& Agricultural Engineering, Oklahoma State University, Stillwater, OK, USA \\ ${ }^{3}$ Department of Horticulture \& Landscape Architecture, Oklahoma State University, Stillwater, OK, USA \\ ${ }^{4}$ Department of Biochemistry \& Molecular Biology, Oklahoma State University, Stillwater, OK, USA \\ Correspondence should be addressed to Danielle Bellmer; danielle.bellmer@okstate.edu
}

Received 6 January 2021; Revised 9 March 2021; Accepted 18 March 2021; Published 26 March 2021

Academic Editor: Antimo Di Maro

Copyright (c) 2021 Reann Garrett et al. This is an open access article distributed under the Creative Commons Attribution License, which permits unrestricted use, distribution, and reproduction in any medium, provided the original work is properly cited.

\begin{abstract}
Brewer's spent grain (BSG) is a processing waste generated in large quantities by the brewing industry. It is estimated that over 38 million tons of BSG is produced worldwide each year and is usually used as animal feed, composted, or thrown into landfills. BSG contains valuable nutritional components, including protein, fiber, and antioxidants. Due to its brittle texture, strong nutty flavors, and dark color profiles, BSG has seen limited use in food products for human consumption. The objective of this study was to develop a palatable chip product that maximized the level of inclusion of BSG. Chips were produced that contained BSG levels ranging from $8 \%$ to $40 \%$, and the physical and sensory properties of the chips were evaluated. Spent grain samples were provided by Iron Monk in Stillwater and were dried at a low temperature and milled into flour for use in the chip formulation. BSG chips were evaluated for water activity, color, and texture (fracture force). An informal sensory evaluation was conducted to evaluate flavor, texture, and probability of purchase using a 5-point hedonic rating scale. Results showed that there were no significant differences in the texture of the chips containing different levels of BSG. The color measurements showed no significant differences between $\mathrm{L}^{*}$ and $\mathrm{a}^{*}$ values for the chips containing different inclusion levels of BSG, but there were some differences in the $\mathrm{b}^{*}$ values. Results from the sensory evaluation showed that consumers preferred the texture of chips with $40 \%$ BSG over chips with $8 \%$ BSG, and they were also more likely to purchase the 40\% BSG chips. There were no significant differences in flavor among the chips containing different inclusion levels of BSG. These results suggest that, for a chip-type product, BSG inclusion levels up to $40 \%$ are possible with positive consumer responses. Development of an alternative value-added product represents an opportunity for breweries nationwide to turn a processing waste into a future asset.
\end{abstract}

\section{Introduction}

Food waste is generated worldwide, as food losses occur throughout the entire food chain. Food processing operations generate a significant amount of waste that ends up in landfills, causing both economic and environmental problems. In many cases, food waste streams contain valuable components that could be converted to valuable products. The beer brewing industry is an example of a food processing operation that generates a significant amount of solid waste. Brewer's spent grain is a byproduct of the brewing industry. The beer brewing process involves the production of wort, where milled barley malt (or other grains) is processed to convert the starch into fermentable sugars. The solids remaining at the end of this process are known as brewer's spent grain (BSG).

The high fiber, protein, and mineral content of brewer's spent grain makes it an attractive ingredient in food products. BSG is rich in polysaccharides, protein, and lignin [1]. There is a great need for added fiber in human diets, which has been shown to improve gastrointestinal function and reduce ulcerative colitis [2]. For many years, the spent grain byproducts were primarily sent to landfills, but the potential health benefits of BSG have resulted in its primary current use as an animal feed. However, the nutrient content of BSG makes it a potentially good candidate to incorporate into human food products, in order to increase its value. In addition, the brewing industry uses materials approved for 
human consumption, so there is real potential for developing new products that can meet regulatory approval [3].

There have been several studies conducted to incorporate spent grain into bakery products such as bread, cookies, and breadsticks; but in those cases, the high fiber content and dark color of the BSG did not allow satisfactory inclusion levels above about 10\% BSG [4-6]. It is hypothesized that the physical properties of BSG would work well in a chip-type product, which would allow much higher inclusion levels of BSG into the product with positive consumer response.

The objectives of this study were to develop a chip product containing high levels of BSG and evaluate the effect of BSG inclusion level on water activity, color, and texture of the chip product.

\section{Materials and Methods}

2.1. Materials. Brewer's spent grain was provided by the local Iron Monk Brewery in Stillwater, OK. Fresh BSG samples were placed into Ziploc freezer bags and kept frozen until use. All other ingredients including vegetable oil (Crisco), vegetable oil spray (Great Value), honey (Great Value), all-purpose flour (Great Value), and salt (Morton Salt) were purchased from the local grocery store.

2.2. Sample Analysis of Brewer's Spent Grain. Proximate analysis was conducted in the Food and Agricultural Products Center's Analytical Services Lab. A wet sample of brewer's spent grain was analyzed for moisture, ash, fat and protein, and the percent carbohydrates was calculated by difference. Triplicate testing was performed for each analysis. The moisture content of wet spent grain samples was determined using Method 950.6-Moisture in Meat [7]. Percent ash of samples was determined using Method 920.153-Ash of Meat [8]. Determination of Crude Protein was by the Leco Combustion Method [9]. Percent fat was measured using the Soxtec method [8].

2.3. Brewer's Spent Grain Flour Preparation. Frozen spent grain samples were thawed at refrigeration temperature for 48 hours and then dried prior to use due to wet BSG being highly susceptible to microbial degradation [1]. Figure 1 shows the wet BSG and BSG flour samples made from Stilly Wheat Ale. Preparation of the BSG flour involved drying thawed samples at $65^{\circ} \mathrm{C}$ for 72 hours and then grinding in a coffee grinder (Mr. Coffee IDS77) for 40 seconds. BSG flour was stored at refrigeration temperature until needed.

2.4. Snack Chip Preparation. Several different potential processes were evaluated for BSG chip formation, but one process was ultimately selected that resulted in the most favorable chip with the highest possible inclusion levels of spent grain. The selected process involved creation of a dough that was pressed, grilled, and then baked. Table 1 shows the chip formulation ingredients for the BSG chips containing 18\% BSG flour. Inclusion of different amounts of
BSG was achieved by substituting brewer's spent grain flour for all-purpose flour used within the formulation. BSG chips were developed with five different inclusion levels of BSG, including $8 \%, 18 \%, 24 \%, 32 \%$, and $40 \%$ BSG.

To form the dough, all dry ingredients were combined in a large mixing bowl, a well was formed in the center for addition of the wet ingredients, and the ingredients were kneaded by hand until a dough was formed. The dough was then weighed into $25 \mathrm{~g}$ balls and then pressed into $5^{\prime \prime}$ discs utilizing a 6 " aluminum tortilla press (Harold Import Co.). The pressed dough was griddled at $149^{\circ} \mathrm{C}$ for 4 minutes per side and then allowed to cool. Once cooled, cooked spent grain flatbreads were cut into 8 triangular pieces and then spread in a single layer on foil lined cookie sheets. Chips were lightly sprayed with vegetable oil ( $3 \mathrm{~g}$ per sheet) and then baked at $176^{\circ} \mathrm{C}$ for 8 minutes.

2.5. Water Activity Analysis. Water activity analysis was conducted using a benchtop water activity meter from Aqualab (Decagon Inc). The average temperature of the sample chamber was $\sim 25^{\circ} \mathrm{F}$. BSG chips were broken into pieces suitable for filling 2 centimeters of the 4-centimeter sample cups. The water activity was recorded for chip samples from the lowest and highest BSG levels. The results are the average of 3 samples per treatment (BSG level). Triplicate testing was performed for each BSG level.

2.6. Color Analysis. A Minolta Spectrophotometer (CM$3500 \mathrm{~d}$ ) was used to measure the reflected color of the BSG chip samples. BSG chips were placed on top of a Petri dish to prevent chip dust from entering the lens of the spectrophotometer. Changes in $\mathrm{L}^{*} \mathrm{a}^{*} \mathrm{~b}^{*}$ were observed as various percentages of BSG were included into formulations. Hue angle was also calculated, and since the $\mathrm{a}^{*}$ and $\mathrm{b}^{*}$ values from the results were both positive (placing them in Quadrant I of the color diagram) the hue angle was calculated from $\tan ^{-1}\left(\mathrm{~b}^{*} / \mathrm{a}^{*}\right)$ [10]. Ten samples were measured from each different treatment (BSG level). Triplicate testing was performed for each BSG level.

2.7. Texture Analysis. A texture analyzer (TA-XT 2i) equipped with a 3-point bend rig and a stainless-steel cylindrical probe $(1 \mathrm{~cm}$ diameter) were used to evaluate the textural properties of the chip samples. The speed of the probe was set to $0.5 \mathrm{~mm} / \mathrm{s}$. Peak force was recorded using the Exponent Stable Microsystems Plus software. Ten samples were measured from each different treatment (BSG level). Triplicate testing was performed for each BSG level.

2.8. Informal Sensory Evaluation. Evaluation of the BSG chips via a full sensory panel was approved in February, 2020 , by the Oklahoma State University Institutional Review Board (IRB-20-57), but due to the Coronavirus pandemic, a full sensory panel was not possible. Instead, an informal sensory analysis was conducted. Participants were approached individually, and social distancing protocols were followed. 


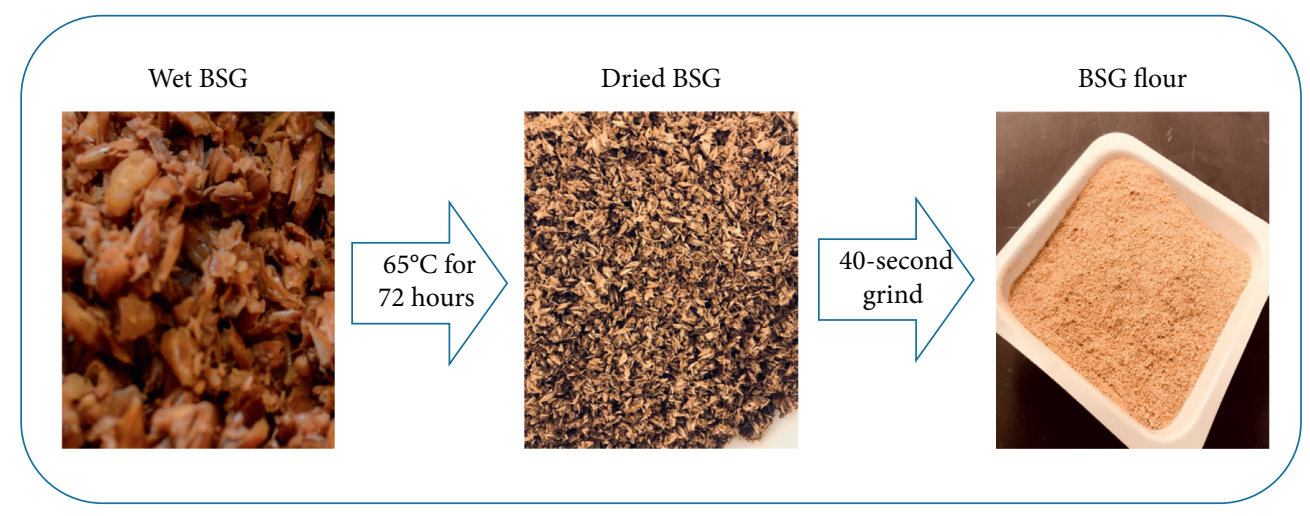

FIgURE 1: Brewer's spent grain flour preparation.

TABLE 1: Ingredients used in the brewer's spent grain chips (BSGC).

\begin{tabular}{lc}
\hline Ingredient & BSGC (g) \\
\hline Brewer's spent grain & 45 \\
All-purpose flour & 80 \\
Water & 79.7 \\
Honey & 28 \\
Oil & 14 \\
Salt & 2.6 \\
\hline
\end{tabular}

The formulation shown contains $18 \%$ inclusion of BSG.

BSG chip samples were prepared 24-48 hours prior to evaluation, according to the methods described above, and stored at room temperature in Ziploc bags. Panelists compared samples containing three different BSG inclusion levels $(8 \%, 18 \%$, and $40 \%)$. Ten panelists were asked to evaluate the samples based on texture, flavor, and possibility of purchase on a 5-point hedonic rating scale. The survey given to panelists is shown in Figure 2.

2.9. Statistical Methods. Triplicate testing was performed for each treatment, with the exception of the sensory panel. The mean values and standard deviations were calculated for all treatments. An ANOVA one-way statistical analysis was used to find differences between data within the results of the color analysis, texture analysis, and sensory analysis observations, where the statistical significance was considered at $p \leq 0.05$. A Tukey-Kramer procedure was performed to further analyze significant differences in pairwise comparisons.

\section{Results and Discussion}

3.1. Proximate Analysis of Spent Grain. The proximate analysis of spent grain from Stilly Wheat Ale is shown in Table 2 . The spent grain contained about $75 \%$ moisture and was $16.85 \%$ protein, $4.87 \%$ fat, and $2.9 \%$ ash on a dry basis. These results are within the ranges of $15 \%-26 \%$ protein, $3 \%-$ $10 \%$ lipids, and about $75 \%$ carbohydrates (dry basis) from previously reported spent grain analyses [11].

3.2. Water Activity Analysis. Table 3 shows the water activity for BSG chips with three different BSG inclusion levels. The water activity ranged from 0.40 to $0.25 a_{\mathrm{w}}$. and decreased as
BSG level increased. Similar results by Guo [12] reported not having a water activity above 0.4 while substituting BSG for all-purpose flour in biscuit (cookie) formulations. Data from Ktenioudaki [5] showed more than a 2\% loss in the moisture content of breadsticks as BSG levels increased from $0 \%$ to $35 \%$. Particle size and water-holding capacity of BSG may be responsible for these observations. Generally, fibrous samples are hard to grind due to their softness and lower density [13], meaning that the flour may not have contained fully uniform particles. Nonuniform particles in conjunction with the higher amounts of protein as BSG levels increased could have affected the water-holding capacity.

3.3. Color Analysis. Figure 3 shows samples of BSG chips at varying levels of BSG inclusion. Visible changes in color were observed as BSG inclusion was increased, but the differences were largely not significant based on quantitative color measurements. Figure 4 shows the color $\mathrm{L}^{*} \mathrm{a}^{*} \mathrm{~b}^{*}$ values for the BSG chips. The $\mathrm{L}^{*}$ value is the luminance component, which corresponds with lightness or darkness, ranging from 0 to 100 [14]. The average $L^{*}$ values ranged from about 32 to 40 for the BSGC samples, but there were no significant differences among the samples. The $\mathrm{a}^{*}$ and $\mathrm{b}^{*}$ are the chromatic components, and the $\mathrm{a}^{*}$ value corresponds with the colors red $(+)$ and green $(-)$, while the $b^{*}$ value corresponds with the colors yellow $(+)$ and blue $(-)$. There were no significant differences among the $\mathrm{a}^{*}$ values for the chips containing different levels of BSG. There were significant differences observed between the $b^{*}$ values of the $24 \%$ and $40 \%$ BSG levels, with the $40 \%$ BSG being lower.

Increased fiber content has sometimes been associated with darker product color, particularly in bread products. In bread products, the crust color is mainly associated with the Maillard and caramelization reactions, but the crumb bread color is usually similar to the color of the ingredients [15]. BSG is darker in color than all-purpose flour, and we would expect BSG flour to produce a darker color product.

Hue angle calculations for all of the BSG chip samples are shown in Table 4. There were no significant differences observed among the hue angle for any of the spent grain chip formulation samples. 
Sample \#

\section{Chip Evaluation Survey}

1. How do you feel about the texture of the chips?

(1-very unsatisfied, 2-unsatisfied, 3-neutral, 4-satisfied, or 5-very satisfied)

$\begin{array}{lllll}1 & 2 & 3 & 4 & 5\end{array}$

2. Did you like the flavor of the chips?

(1-very unsatisfied, 2-unsatisfied, 3-neutral, 4-satisfied, or 5-very satisfied)

$\begin{array}{lllll}1 & 2 & 3 & 4 & 5\end{array}$

3. Would you consider purchasing these chips from a store?

(1-very unlikely, 2-unlikely, 3-neutral, 4-likely, or 5-very likely)

$\begin{array}{lllll}1 & 2 & 3 & 4 & 5\end{array}$

Figure 2: Survey given to panelists to evaluate six different chip formulations. Each response is based on a 5-point hedonic scale.

TABle 2: Proximate analysis of spent grain from Stilly Wheat Ale (Iron Monk Brewery).

\begin{tabular}{lcc}
\hline \multicolumn{2}{l}{ Brewer's spent grain proximate analysis } & \\
& Wet basis (\%) & Dry basis (\%) \\
\hline Moisture & $74.96 \pm 0.04$ & - \\
Ash & $0.73 \pm 0.01$ & $2.9 \pm 0.03$ \\
Fat & $1.22 \pm 0.02$ & $4.87 \pm 0.09$ \\
Protein & $4.22 \pm 0.04$ & $16.85 \pm 0.14$ \\
Carbohydrates & $18.88 \pm 0.08$ & $75.37 \pm 0.23$ \\
\hline
\end{tabular}

Values shown are the average \pm standard deviation for three samples.

TABLE 3: Water activity $\left(a_{\mathrm{w}}\right)$ of BSG chip product samples.

\begin{tabular}{lccc}
\hline \multicolumn{4}{l}{ BSG chip water activity $\left(a_{\mathrm{w}}\right)$} \\
\hline \multirow{2}{*}{$\%$ BSG } & $8 \%$ & $32 \%$ & $40 \%$ \\
Mean $a_{\mathrm{w}} \pm$ SD & $0.4095 \pm 0.03$ & $0.3456 \pm 0.02$ & $0.2507 \pm 0.04$
\end{tabular}

Values shown are mean \pm SD. $n=3$ replications, with 3 subsamples per treatment.

3.4. Texture Analysis. The texture of the BSG chips was assessed using a 3-point bend test to determine fracture force. Fracture force is the maximum force required to break samples [16]. Figure 5 shows the average peak force and standard deviation for the BSG chips made with five different levels of BSG inclusion. There were no significant differences observed among the BSG chip samples, although there is a trend showing lower fracture force at higher levels of BSG inclusion. The texture of chips with lower BSG

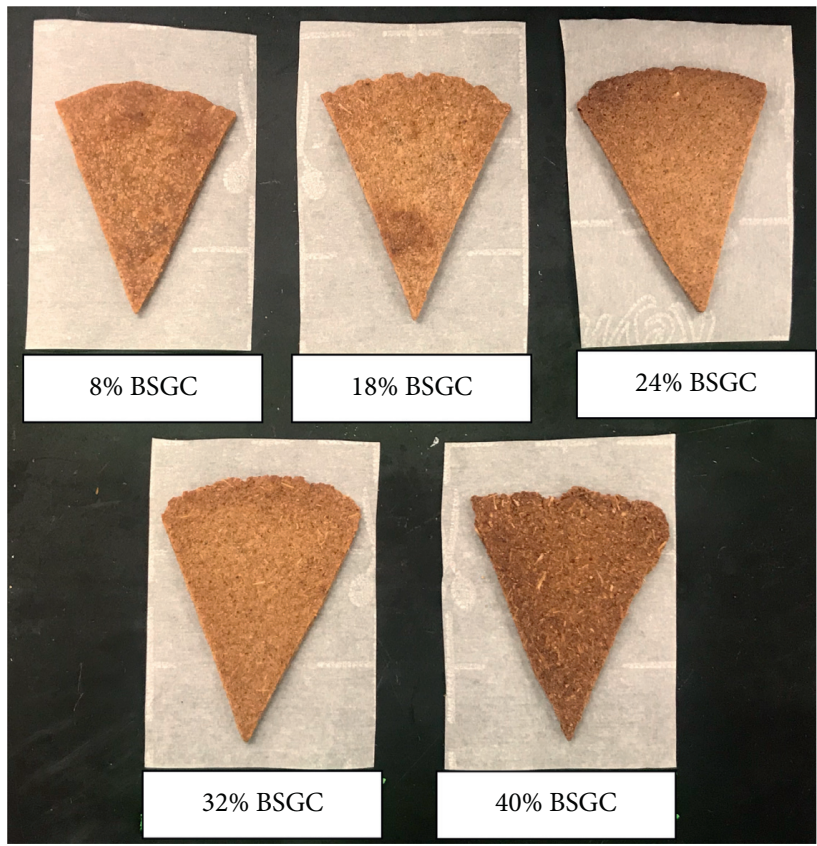

FIGURE 3: Brewer's spent grain chip samples with varying levels of inclusion of BSG.

inclusion was often tough, leathery, and fracture resistant. These results are common among baked goods made with flour containing higher amounts of fiber such as wheat bran. Ktenioudaki [5] experienced similar results while assessing snap test results using breadsticks that contained various 


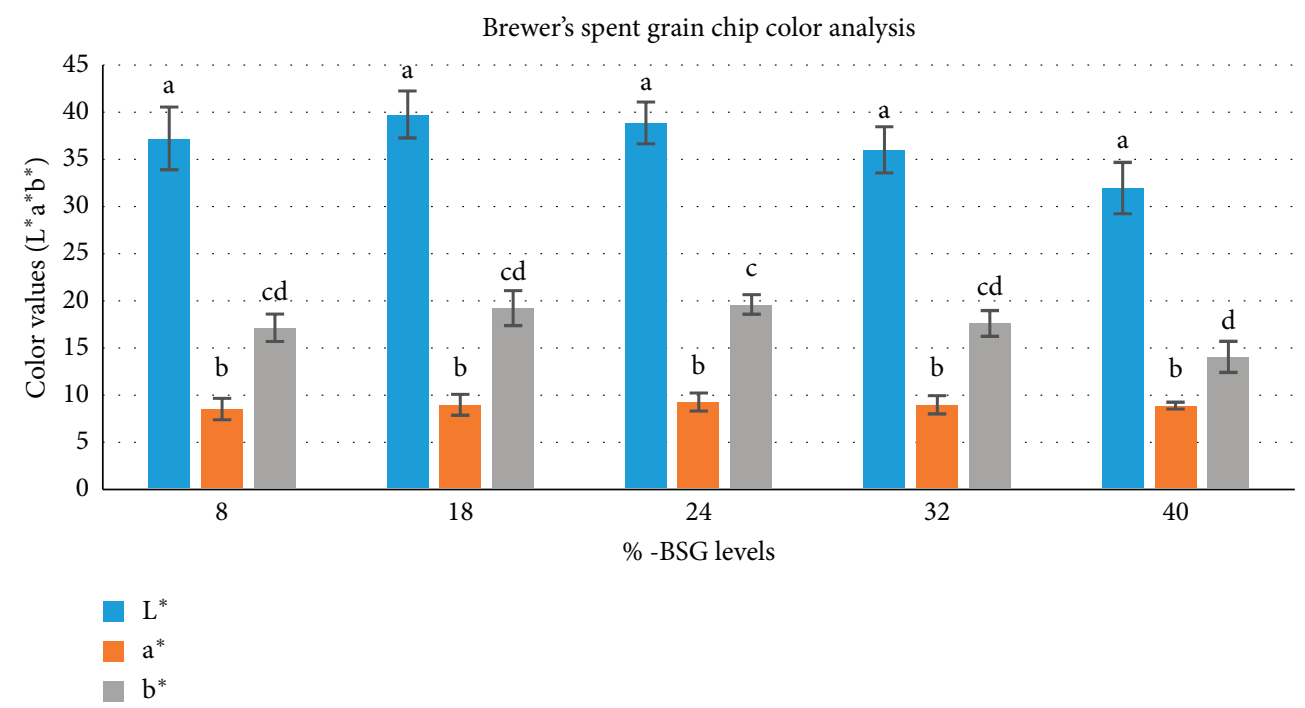

FIGURE 4: $\mathrm{L}^{*}, \mathrm{a}^{*}$, and $\mathrm{b}^{*}$ color values for brewer's spent grain chip samples. Values shown are mean \pm standard deviation; $n=3$ replications, with 10 subsamples per treatment. Values accompanied by the same letter have means that are not significantly different $(p \leq 0.05)$.

TABLE 4: Calculated hue angle values for BSGC samples.

\begin{tabular}{lc}
\hline BSG inclusion & Hue angle $\left(\mathrm{H}^{\circ}\right)$ \\
\hline $8 \%$ BSG & $63.77 \mathrm{a}$ \\
$18 \%$ BSG & $65.07 \mathrm{a}$ \\
$24 \%$ BSG & $65.90 \mathrm{a}$ \\
$32 \%$ BSG & $63.14 \mathrm{a}$ \\
$40 \%$ BSG & $57.64 \mathrm{a}$ \\
\hline
\end{tabular}

Columns accompanied by the same letter have means that are not significantly different $(p \leq 0.05)$.

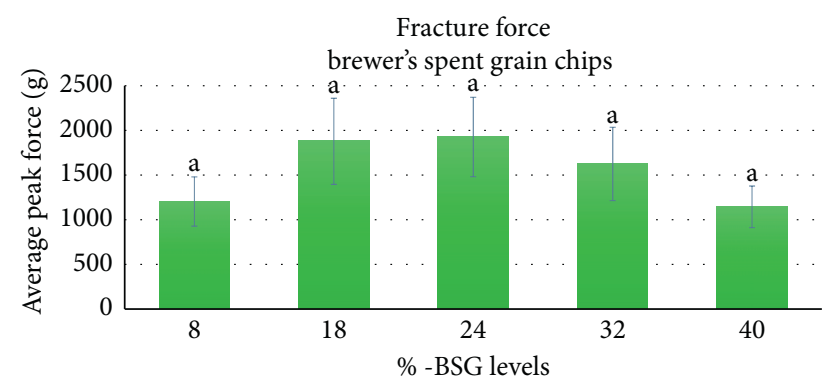

FIGURE 5: Three-point bend peak force of BSG chips made with varying levels of BSG inclusion. Values shown are mean \pm S.D. $n=3$ replications, with 10 subsamples per treatment. Columns accompanied by the same letter have means that are not significantly different $(p \leq 0.05)$.

amounts of BSG. In general, chips containing higher BSG inclusion levels were crisper, which could result in a lower fracture force.

3.5. Informal Sensory Analysis. Chips with three different BSG inclusion levels were evaluated. Panelists were asked to assess samples for color, texture, and whether they would buy the product, and responses are shown in Table 5. There were some significant differences between the samples made with different BSG inclusion levels. Panelists clearly liked the
TABLE 5: Mean responses from informal sensory analysis of brewer's spent grain chip (BSGC) samples with three different BSG inclusion levels $(n=10)$.

\begin{tabular}{lcccc}
\hline \multicolumn{5}{l}{ BSG inclusion levels } \\
\hline Treatment & $8 \%$ & $18 \%$ & $40 \%$ & $P$-value \\
Texture & $1.8 \mathrm{a}$ & $3.9 \mathrm{~b}$ & $4.3 \mathrm{~b}$ & $<0.0001^{*}$ \\
Flavor & $3.6 \mathrm{a}$ & $3.9 \mathrm{a}$ & $3.5 \mathrm{a}$ & 0.3841 \\
Purchase & $1.6 \mathrm{a}$ & $3.6 \mathrm{~b}$ & $3.7 \mathrm{~b}$ & $<0.0001^{*}$ \\
\hline
\end{tabular}

${ }^{*}$ Means within the same row accompanied by the same letter are not significantly different $(p \leq 0.05)$.

texture of the chips with higher BSG inclusion levels more than the $8 \%$ inclusion level, and they were more likely to purchase the chips with higher inclusion rates. There were no significant differences in flavor, indicating that higher levels of BSG did not negatively impact the flavor of the chips.

These results are noteworthy, because in previous attempts to incorporate BSG into human food products, higher inclusion levels have consistently resulted in unfavorable evaluations, especially in products such as breads and cookies $[4,5]$. For these chip products, panelists actually preferred the texture of the chips with higher inclusion rates and were more likely to purchase chips containing 40\% BSG than chips containing $8 \%$ BSG.

\section{Conclusions}

A new chip product was developed containing brewer's spent grain, with the goal of maximizing BSG inclusion levels. Resultant chips containing up to $40 \%$ BSG inclusion levels showed physical and sensory properties that were equal to or better than the chips containing 8\% BSG. A texture analysis of the chip products revealed no significant differences among chips with varying levels of BSG. A color analysis of the chips showed some significant differences in the $b^{*}$ values between chips with varying levels of BSG, but 
the $\mathrm{L}^{*}$ and $\mathrm{a}^{*}$ values were not significantly different. Sensory analysis of chips containing three different levels of BSG revealed that consumers actually preferred the texture of chips with $40 \%$ BSG over the chips with $8 \%$ BSG and were more likely to purchase the $40 \%$ BSG chips. These results are meaningful, because previous attempts to incorporate BSG into food products have resulted in BSG inclusion levels limited to about $10 \%$ due to lack of consumer acceptance of its high fiber and dark color. The new chip product takes advantage of the texture and the color of the BSG in order to maximize inclusion levels. Development of a new valueadded product from brewer's spent grain could provide breweries with an alternative way to utilize an unavoidable waste.

\section{Data Availability}

All data collected in support of this study are available from the corresponding author upon request.

\section{Disclosure}

This work was presented as a poster at the ASABE Annual International Meeting (virtual event) in 2020 on July 13-15, 2020 .

\section{Conflicts of Interest}

The authors declare that they have no conflicts of interest.

\section{Acknowledgments}

The authors thank Iron Monk Brewery in Stillwater, Oklahoma, for supplying the brewer's spent grain. This work was supported in part by USDA\#2016-11407 NIFA National Needs Fellowship Grant.

\section{References}

[1] J. A. Robertson, K. J. A. I'Anson, J. Treimo et al., "Profiling brewers' spent grain for composition and microbial ecology at the site of production," LWT-Food Science and Technology, vol. 43, no. 6, pp. 890-896, 2010.

[2] W. F. Broekaert, C. M. Courtin, K. Verbeke, T. Van de Wiele, W. Verstraete, and J. A. Delcour, "Prebiotic and other healthrelated effects of cereal-derived arabinoxylans, arabinoxylanoligosaccharides, and xylooligosaccharides," Critical Reviews in Food Science and Nutrition, vol. 51, no. 2, pp. 178-194, 2011.

[3] V. Stojceska and P. Ainsworth, "The effect of different enzymes on the quality of high-fibre enriched brewer's spent grain breads," Food Chemistry, vol. 110, no. 4, pp. 865-872, 2008.

[4] S. Ozturk, O. Ozboy, I. Cavidoglu, and H. Koksel, "Effects of brewer's spent grain on the quality and dietary fibre content of cookies," Journal of the Institute of Brewing, vol. 108, pp. 23-27, 2002.

[5] A. Ktenioudaki, V. Chaurin, S. F. Reis, and E. Gallagher, "Brewer's spent grain as a functional ingredient for breadsticks," International Journal of Food Science \& Technology, vol. 47, no. 8, pp. 1765-1771, 2012.

[6] D. M. Waters, F. Jacob, J. Titze, E. K. Arendt, and E. Zannini, "Fibre, protein and mineral fortification of wheat bread through milled and fermented brewer's spent grain enrichment," European Food Research and Technology, vol. 235, no. 5, pp. 767-778, 2012.

[7] A. International, G. E. Latimer, and W. E. Horwitz, "AOAC official method 950.46-moisture in Meat," JAOAC, vol. 33, p. 749, 1950.

[8] George, Ed., Official Methods of Analysis, L. George, Ed., Association of Official Analytical Chemists, Rockville, MD, USA, 18th edition, 2010.

[9] MD Rockville, Ba 4e-93- Generic Combustion Method for Determination of Crude Protein, AOCS Official Mehods, Rockville, MD, USA, 5th edition, 2004.

[10] M. R. McLellan, L. R. Lind, and R. W. Kime, "Hue angle determinations and statistical analysis for multiquadrant hunter L,a,b data," Journal of Food Quality, vol. 18, no. 3, pp. 235-240, 1994.

[11] P. S. Nigam, "An overview: recycling of solid barley waste generated as a by-product in distillery and brewery," Waste Management, vol. 62, pp. 255-261, 2017.

[12] M. Guo, J. Du, Z. A. Zhang, K. Zhang, and Y. Jin, “Optimization of brewer's spent grain-enriched biscuits processing formula," Journal of Food Process Engineering, vol. 37, no. 2, pp. 122-130, 2014.

[13] B.-K. Kim, Y.-G. Chun, A.-R. Cho, and D.-J. Park, "Reduction in fat uptake of doughnut by microparticulated wheat bran," International Journal of Food Sciences and Nutrition, vol. 63, no. 8, pp. 987-995, 2012.

[14] K. L. Yam and S. E. Papadakis, "A simple digital imaging method for measuring and analyzing color of food surfaces," Journal of Food Engineering, vol. 61, no. 1, pp. 137-142, 2004.

[15] M. Gómez, F. Ronda, C. A. Blanco, P. A. Caballero, and A. Apesteguía, "Effect of dietary fibre on dough rheology and bread quality," European Food Research and Technology, vol. 216, no. 1, pp. 51-56, 2003.

[16] A. Kayacier and R. K. Singh, "Textural properties of baked tortilla chips," LWT-Food Science and Technology, vol. 36, no. 5, pp. 463-466, 2003. 